\title{
CATARACT SURGERY?
}

IS TOPICAL ANESTHESIA FOR ALL IS A FUTURE IN CATARACT SURGERY? A COMPARISON BETWEEN TOPICAL \& RETROBULBAR ANESTHESIA IN TERMS OF PAIN DURING CATARACT SURGERY

1. Consultant Eye Surgeon, Bahawal Victoria Hospital, Bahawalpur.

2. Associate Professor of Ophthalmology, Quaid e Azam Medical College, Bahawalpur.

3. Assistant Professor of Ophthalmology, Dow Medical College, Karachi.

Correspondence Address: Dr Rao Muhammad Rashad Qamar Associate Professor of

Ophthalmology

29/B, Medical Colony, Bahawalpur. drrashadqr@yahoo.com

Article received on:

04/05/2015

Accepted for publication:

01/06/2015

Received after proof reading: 08/08/2015

\section{INTRODUCTION}

Cataract surgery is the most commonly performed surgical procedure in Ophthalmology. During the recent years, cataract surgery has undergone major evolutionary changes. These include the use of phacoemulsification and foldable intra ocular lenses (IOLs). There is an ever increasing stress on the ophthalmic surgeons regarding the techniques of anesthesia that are safe, effective, free from complications, and allow rapid visual recovery. With the improvements in surgical techniques for cataract extraction, ophthalmic anesthesia techniques have also undergone similar refinements. Different anesthesia techniques have been used for cataract surgery including retrobulbar, parabulbar (Sub-Tenon), peribulbar, sub-conjunctival, topical, and general anesthesia. Topical anesthesia is where local anesthetic eye drops are applied to the surface of the eye. ${ }^{1,2}$

Its non-invasiveness and easy to administrator with minimal to absent discomfort, rapid in onset and most importantly reduces the potential risks associated with retrobulbar injections coupling with the rapid visual recovery after surgery makes this method more suitable choice for the surgeons as well as for the patients. ${ }^{3}$ It is now being increasingly used both by the senior surgeons and residents as well. ${ }^{4}$ However, topical anesthesia demands patient education and cooperation. Topical anesthesia only blocks the trigeminal nerve endings, providing the best "complete" analgesia of the eye. The patient's optic nerve and motor neurons are typically not affected, resulting in fully preserved ocular motility.

Retrobulbar anesthesia, where anesthetic drugs are injected into the orbit behind the eye ball (retrobulbar space), is associated with many complications including glob perforation.., 6 However it is still widely used for the intraocular procedures including cataract surgery.

Every method of local anesthesia has its own merits and demerits. Multiple studies have compared different techniques regarding their efficacy, duration, risks and benefits. ${ }^{7,8}$ Thus need 
for consensus over the evolution of the ideal anesthetic technique is growing. The proposed study compares the topical with retrobulbar anesthesia regarding its effectiveness in terms of pain relief during cataract surgery. The results of this study give us a chance to critically review our current anesthesia techniques for the cataract surgery and will be helpful for residents in future to choose the better of two anesthesia techniques regarding pain relief.

\section{PATIENTS AND METHODS}

This comparative study was conducted at Department of Ophthalmology, Bahawal Victoria Hospital Bahawalpur from 18 $8^{\text {th }}$ July, 2012 to $18^{\text {th }}$ January, 2013. Total 100 patients with cataract were included in this study. An approval was taken from institutional review committee and written informed consent was taken from every patient.

Patients having age $\geq 50$ years either male or female with cataract and visual acuity less than $6 / 36$ on Snellen's testing were included in this study. Patients who refused consent for cataract surgery, having language difficulties, history of hypersensitivity to anesthetic drugs and with past history of retrobulbar hemorrhage as a complication of retrobulbar block were excluded from the study. Patients were randomly divided into two equal groups. Patients managed with topical anesthesia were labelled as TA Group and patients managed with retrobulbar anesthesia were labelled as RA Group.

All patients were undergone thorough ophthalmic examination before surgery including best corrected visual acuity (BCVA), Ocular motility examination, pupillary reactions, slit lamp biomicroscopy and fund us examination by 90D and indirect ophthalmoscopy. A scan and keratometer were used to calculate the power of intraocular lens. Complete systemic examination of every patient was done whenever needed by a concerned medical specialist.

On completion of the operation, each patient was shown a visual analog pain scale (VAS) with numeric and descriptive ratings from pain score
$0=$ no pain (baseline), pain score $1-4=$ mild pain, pain score $5-8=$ moderate pain, pain score $9-12=$ severe pain to rate the level of pain felt during the operation, including the pain felt after operation up to how many duration in hours. If patients were unable to read the printed numbers and descriptive text on the pain scale, the examiner read them for each patient and asked about the intensity of ocular pain experience by him/her during cataract surgery. The effectiveness of anesthesia (in term of pain relief) was taken as $+v e$ in the patents in whom pain score is from 0 to 4 (No or mild) and effectiveness of anesthesia was taken as -ve in patients having pain score from 5 to 12 (moderate to severe). Demographic profile of the patients and information regarding effectiveness of anesthesia was entered in predeigned profroma.

All the collected data was entered in SPSS version 17 and analyzed accordingly. The quantitative data was presented as mean \pm SD. The qualitative data was presented as frequency and percentage. Chi-square test was applied to compare the effectiveness between the both groups.

Stratification with respect to age, duration of symptoms and gender was done. Post stratification. Chai-square test was applied to see the level of significance. P-values $\leq 0.05$ was considered statistically significant.

\section{RESULTS}

Total 100 patients undergoing cataract surgery were included in this study. Mean age of the patient was $64.14 \pm 8.7$ years (age range from $50-80$ years). Patients in retrobulbar anesthesia group who reported the pain scores (0-4) during cataract surgery, were 46 (effectiveness was positive in $92 \%$ patients), while in Topical anesthesia group were 33 (effectiveness was positive in $66 \%$ patients). This is showing that the difference between the effectiveness of these two anesthesia is statistically significant $(P=.0014)$. More number of patients of retrobulbar group remained comfortable during cataract surgery as compare to topical anesthesia group.(Table-I) 


\begin{tabular}{|c|c|c|c|}
\hline Effectiveness & RA (\%) & TA (\%) & P-value \\
\hline +ve & $46(92 \%)$ & $33(66 \%)$ & \multirow{2}{*}{0.0014} \\
\hline -ve & $4(8 \%)$ & $17(33 \%)$ & \\
\hline
\end{tabular}

Table-I. Effectiveness of anesthesia (in term of pain relief) in both groups

Duration of symptoms (complaint of pain even mild pain) remained $5.68+2.60 \mathrm{hrs}$ in all patients. It was statistically significant $(P=0.0001)$ when compared between these two groups of anesthesia that either complaint of pain remain $\leq 5 \mathrm{hrs}$ or $>5 \mathrm{hrs}$. Only $14(28 \%)$ patients in Retrobulbar group complained of pain (even mild pain) after 5 hrs of surgery while $35(70 \%)$ patients in topical group. (Table-II)

\begin{tabular}{|c|c|c|c|}
\hline Duration & RA (\%) & TA (\%) & P-value \\
\hline$\leq 5$ hrs & $36(72 \%)$ & $15(30 \%)$ & \multirow{2}{*}{0.0001} \\
\hline$>5$ hrs & $14(28 \%)$ & $35(70 \%)$ & \\
\hline \multicolumn{2}{|c|}{ Table-II. Duration of symptoms (pain even mild) } \\
In total patients n=100 \\
\hline
\end{tabular}

Difference between the effectiveness of 2 study groups in age group 50-60 years was not statistically significant $(P=0.6077)$ but in age group 61-70 years $P$ value was found to be 0.0379 and in age group 71-80 $P$ value was 0.0093 that is statistically very significant, this shows that young patients are more cooperative as compared to old age patients. (Table-III)

\begin{tabular}{|c|c|c|c|}
\hline Effectiveness & RA (\%) & TA (\%) & p-value \\
\hline \multicolumn{4}{|c|}{ Age group $50-60$ years } \\
\hline+ ve & 22 (88\%) & 14 (82.35\%) & \multirow{2}{*}{0.6077} \\
\hline$-v e$ & $3(12 \%)$ & $3(17.65 \%)$ & \\
\hline \multicolumn{4}{|c|}{ Age group $61-70$ years } \\
\hline+ ve & $11(91.67 \%)$ & $12(57.15 \%)$ & \multirow{2}{*}{0.0379} \\
\hline$-\mathrm{ve}$ & $1(8.33 \%)$ & $9(42.85 \%)$ & \\
\hline \multicolumn{4}{|c|}{ Age group $71-80$ years } \\
\hline+ ve & $13(100 \%)$ & $7(58.33 \%)$ & \multirow{2}{*}{0.0093} \\
\hline$-v e$ & 0 & $5(41.66 \%)$ & \\
\hline \multicolumn{4}{|c|}{$\begin{array}{c}\text { Table-III. Effectiveness of anesthesia (in term of pain } \\
\text { releif) }\end{array}$} \\
\hline
\end{tabular}

After comparing effectiveness of between the gender of both groups, the statistical difference was found with $\mathrm{P}=0.0002$ in female group. Effectiveness was positive in $96 \%$ females of retrobulbar anesthesia group while in 56\% females of Topical anesthesia group. This significant difference shows that female are more anxious and conscious regarding pain than male in which the $\mathrm{P}$ value was 0.6773 . (Table-IV)

\begin{tabular}{|c|c|c|c|}
\hline Effectiveness & RA (\%) & TA (\%) & p-value \\
\hline \multicolumn{4}{|c|}{ Female $(n=60)$} \\
\hline+ ve & 29 (96.6\%) & 17 (56\%) & \multirow{2}{*}{0.0002} \\
\hline$-v e$ & $1(3.3 \%)$ & 13 (44\%) & \\
\hline \multicolumn{4}{|c|}{ Male $(n=40)$} \\
\hline+ ve & $17(85 \%)$ & $16(80 \%)$ & \multirow{2}{*}{0.6773} \\
\hline$-v e$ & 3 (15\%) & $4(20 \%)$ & \\
\hline \multicolumn{4}{|c|}{$\begin{array}{l}\text { Table-IV. Effectiveness of anesthesia (in term of pain } \\
\text { releif) for male and female }\end{array}$} \\
\hline
\end{tabular}

Intraoperatively, manipulation of the iris, distention of the anterior chamber, and rotation of the IOL most often led to verbalization of this patient's discomfort. Additional local anesthesia was required in 4 (8\%) patients of retrobulbar local anesthesia group where as in topical anesthesia group 17 case (33\%) received additional dose. In the topical anesthesia group, only $50 \%$ patients said they would operate for this type of anesthesia for the second eye, while $83 \%$ of the patients in the retrobulbar anesthesia group stated a preference for this retrobulbar anesthesia.

Anesthesia-related chemosis, periorbital hematoma, and subconjunctival hemorrhage occurred only in the retrobulbar anesthesia group but none patient suffered from any serious complication like retrobulbar hemorrhage, and never led to complete cancellation or significant delay of the planned surgical intervention, and no one patient was excluded from the study. The incidences of other intraoperative complications did not differ significantly between the 2 study groups except that surgeon remained more conscious and discomfort in operating Topical anesthesia group's patients. In the first 24 hours, no severe complications were observed in either of the 2 study groups. 
There was adequate akinesia in retrobulbar group as compared to topical group where the no akinesia was observed. Total akinesia of eyeball was found in $45(90 \%)$ cases of retrobulbar local anesthesia.

\section{DISCUSSIONS}

Most commonly performed refractive procedure is cataract surgery all over the world. The primary purpose in managing a patient with cataract, as stated in the American Academy of Ophthalmology "Preferred Practice Pattern for Cataract in the Adult Eye", ${ }^{9}$ is to improve functional vision and the quality of life.

In our study, we compared the effectiveness of retobulbar anesthesia and topical anesthesia in term of pain relief and tried to find out a good anesthetic for pain relief. More retobulbar anesthesia group patients indicate pain free surgery than topical anesthesia group patients $(P=0.0014)$. Gombos et al reported that the $14 \%$ patients with topical anesthesia experience pain while the $4 \%$ patient with retobulbar anesthesia feel the pain during cataract surgery. ${ }^{10} \mathrm{In}$ another study, it is described that topical anesthesia patient felt more pain than with retobulbar Anesthesia $(p<0.001) .{ }^{11}$

Cataract surgery under topical anesthesia is usually completed in shorter time and postoperative uncorrected visual acuity improves faster, ${ }^{3}$ without postoperative diplopia. ${ }^{12}$ On the other hand, retobulbar techniques can cause post-operative akinaesia, which is not desirable in day care surgery as no or early pad off is an important consideration in day care surgery.

Another limitation in TA group during the surgery was that patients were more awake, did not co-operate well (e.g. by blinking/squeezing) and were more worried/conscious about the procedure. It was observed more in the young and anxious patients especially females(The iris and ciliary muscle retain their sensitivity).We tried to solve the problem with verbal communication, but this was felt as ineffective. We tried to avoid intravenous sedation and opioids, despite reports that these can reduce pain during the procedure, because of the related side effects.

The limitation of study was the appropriate use of Visual analogue scale as the grading perception could be different in every patient according to his pain threshold, so it became very difficult that how to judge the pain which the patient felt. Surgeon's assessment was not considered in my study that could be very helpful to collaborate the results regarding his difficulties. Collective numbers of patients was relatively small, and it was difficult to generalize the results. However surgery was performed by only one experienced surgeon using the same surgical technique.

In future we should consider the surgeon's preferences (both seniors and learners) for choosing anesthesia along with considering patient's comfort.

Finally, regardless of which modification is used, the importance of monitored anesthesia care attending the patient undergoing local techniques for cataract surgery cannot be overemphasized, as in more than one third of such cases intervention by anesthetic personnel is required for the safe conclusion of the operation.

\section{CONCLUSION}

It is observed that topical anesthesia in cataract surgery is a simple, safe and noninvasive technique but it cannot be proposed as a very good alternative to retro bulbar anesthesia in cataract surgery of all patients regarding its effectiveness in terms of pain relief.

Copyright@ 01 June, 2015.

\section{REFERENCES}

1. Tranos PG, Wickremasinghe SS, Sinclair N, Foster PJ, Asaria $R$, Haris $M L$, et al. Visual perception during phacoemulsification cataract surgery under topical and regional anaesthesia. Acta Ophthalmol Scand. 2003;81:118-22.

2. Wells AP, Maslin K. Diplopia from peribulbar ropivicaine. Clin Experiment Ophthalmol. 2000 Feb;28(1):32-3.

3. Rizvi Z, Rehman T, Malik S, Qureshi A, Paul L, Qureshi, et al. An evaluation of topical and local anesthesia in 
phacoemulsification. J Pak Med Assoc. 2003;53:16770.

4. Randleman JB, Strivatava SK, Aqrom MM. Phacoemulsification with topical anaesthesia performed by resident surgeons. J Cataract Refract Surg. 2004;30:149-54.

5. Haider SA, Lateef Q. Globe perforation during retrobulbar anaesthesia: causes and management. Pak J Ophthalmol. 2002;18:102-5.

6. Ashaye AO, Ubah JN, Sotumbi PT. Respiratory arrest after retrobulbar anaesthesia. West Afr J Med. 2002 Oct-Dec;21(4):343-4.

7. Sauder G, Jonas JB. Topical versus peribulbar anaesthesia for cataract surgery. Acta ophthalmol Scand. 2003;81:596-8.

8. Borel M, Ousmane L, Lebuffe G, Robin E, Cantineau $D$, Vallet $B$, et al. Lidocaine vs. mepivacaine for peribulbar anaesthesia in cataract surgery : a randomize double-blind study. Eur J Anaesthesiol. 2006 Jun;23(6):532-4.

9. American Academy of Ophthalmology: Cataract in the Adult Eye: Preferred Practice Pattern. San Francisco: American Academy of Ophthalmology, 2001.

10. Gombos K, Jakubovits E, Kolos A, Salacz G, Nemeth J. Cataract surgery anaesthesia is topical anaesthesia really better than retrobulbar. Acta Ophthalmol. Scand.2007;85:309-16.

11. Boezaart A, Berry R, Nell M. Topical anaesthesia versus retrobulbar block for cataract surgery: the patients' perspective. J Clin Anesth, 2000;12:58-60.

12. Yanguela J, Gomez-Arnau JI, Martin-Rodrigo JC, et al: Diplopia after cataract surgery. Comparative results after topical or regional injection anesthesia. Ophthalmology 111:686, 2004.



